\title{
Intervenção profissional do assistente social e as condições de trabalho no Suas*
}

\section{The social worker's professional intervention and working conditions at Suas}

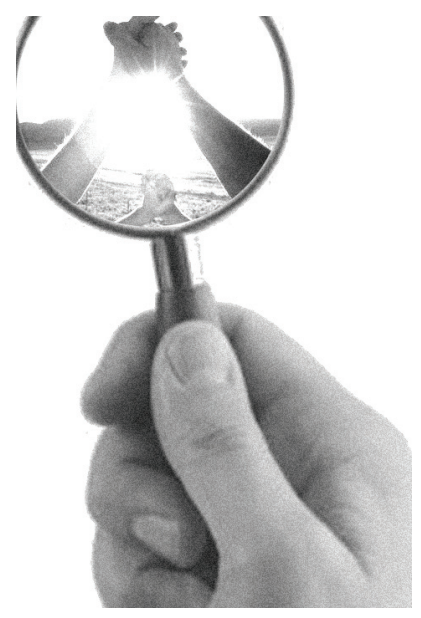

Raquel Raichelis ${ }^{*}$

\begin{abstract}
Resumo: Este artigo tem por objetivo discutir o trabalho do assistente social no âmbito do Sistema Único de Assistência Social (Suas), enquanto espaço sócio-ocupacional do assistente social e de outros profissionais, que amplia o mercado de trabalho e abre novas possibilidades de intervenção profissional, ao mesmo tempo em que precariza e intensifica os processos de trabalho, tensionando as formas de efetivação do projeto ético-político profissional do serviço social.
\end{abstract}

Palavras-chave: Serviço Social. Trabalho. Suas. Precarização. Projeto profissional.

\begin{abstract}
This article aims at discussing the professional practice of the social worker in the context of the Sistema Único de Assistência Social - Suas. It intends to address the system as a socio-occupational space for social workers and other professionals, which enhances the labor market and opens new possibilities for professional intervention. However, it takes place concurrently with the precarization and intensification of the working process, putting pressure on the strategies for the realization of the ethical-political professional project of social work.
\end{abstract}

Keywords: Social Work. Work. Suas. Precarization. Professional project.

* Este artigo está baseado na palestra proferida em mesa-redonda do $3^{\circ}$ Seminário Anual de Serviço Social: O Serviço Social frente aos desafios do século XXI - crise do capitalismo, novos modelos de desenvolvimento e as repercussões na formação e na intervenção profissional, promovido pela Cortez Editora em maio de 2010, no Tuca, auditório da PUC-SP.

** Assistente social; mestre e doutora em Serviço Social pela PUC-SP; coordenadora do Núcleo de Estudos e Pesquisas sobre Trabalho e Profissão do Programa de Estudos Pós-Graduados em Serviço Social da PUC-SP, São Paulo, Brasil; pesquisadora da Coordenadoria de Estudos e Desenvolvimento de Projetos Especiais da PUC-SP (Cedpe); atual coordenadora do Programa de Estudos Pós-Graduados em Serviço Social da mesma universidade (2009-11). 


\section{Introdução}

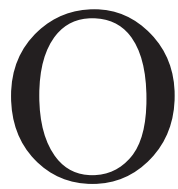

trabalho do assistente social tem sido um tema presente na agenda profissional, e vem ganhando centralidade crescente nos debates de profissionais estudantes e pesquisadores do Serviço Social, sinalizando a premência de estudos e pesquisas que desvendem o processamento do trabalho do assistente social (Iamamoto, 2007) e as formas por ele assumidas nos diferentes espaços ocupacionais e nas diversas atividades que desenvolvem no cotidiano das instituições públicas e privadas.

As transformações contemporâneas que afetam o mundo do trabalho, seus processos e sujeitos provocam redefinições profundas no Estado e nas políticas sociais, desencadeando novas requisições, demandas e possibilidades ao trabalho do assistente social no âmbito das políticas sociais.

A implantação do Suas e sua rápida expansão por todo o território nacional vem ampliando consideravelmente o mercado de trabalho para os assistentes sociais e demais profissionais atuantes nessa área. Ao mesmo tempo e no mesmo processo, contraditoriamente, aprofundam a precarização das condições em que este trabalho se realiza, considerando o estatuto de trabalhador assalariado do assistente social, subordinado a processos de alienação, restrição de sua autonomia técnica e intensificação do trabalho a que estão sujeitos os trabalhadores assalariados em seu conjunto.

Ainda que a política de assistência social seja um campo de trabalho multiprofissional e interdisciplinar, ela se constitui historicamente como uma das principais mediações do exercício profissional dos assistentes sociais, sendo reconhecidos socialmente (e se autorreconhecendo) como os profissionais de referência desta política, apesar das ambiguidades que cercam essa relação de longa data. ${ }^{1}$

Problematizar estas questões no contexto da análise dos espaços sócio-ocupacionais e das novas configurações que assume o trabalho e as demandas profissio-

1. Na hierarquia das práticas profissionais, a assistência social foi secundarizada, especialmente a partir do Movimento de Reconceituação na América Latina, que fez a crítica radical ao assistencialismo e ao conservadorismo profissional, marcas históricas das ações deste campo. Apesar da luta empreendida pela categoria profissional e pela direção política das entidades profissionais para a transformação da assistência social em política pública de seguridade social, comprometida com a expansão de direitos, permanece um movimento ambíguo de afirmação/recusa, continuidade/ruptura diante da premência das necessidades sociais e a precariedade das respostas institucionais. 
nais, bem como os processos e condições de trabalho do assistente social (e demais trabalhadores sociais) no Suas, são as finalidades deste artigo.

\section{Espaços sócio-ocupacionais e trabalho do assistente social - situando algumas premissas}

Analisar os espaços sócio-ocupacionais do assistente social exige inscrever a reflexão no movimento histórico da sociedade brasileira e mundial, considerando os processos sociopolíticos que condicionam o modo como o Serviço Social se insere na sociedade capitalista madura, como um tipo de especialização do trabalho inscrito na divisão sociotécnica do trabalho, articulado aos processos de produção e reprodução das relações sociais. ${ }^{2}$

Ao mesmo tempo, para além das dimensões objetivas que conferem materialidade ao fazer profissional, é preciso considerar também, e de forma nem sempre convergente, o modo pelo qual o profissional incorpora na sua consciência o significado do seu trabalho, as representações que faz da profissão, a intencionalidade de suas ações, as justificativas que elabora para legitimar sua atividade - que orientam a direção social do exercício profissional.

Nesses termos, é importante demarcar de saída que refletir sobre os espaços sócio-ocupacionais do serviço social implica considerá-los como expressões das dimensões contraditórias do fazer profissional, nos quais se condensam e se confrontam concepções, valores, intencionalidades, propostas de sujeitos individuais e coletivos, articulados em torno de distintos projetos em disputa no espaço institucional onde se implementam políticas públicas.

No caso em questão, interessa-nos analisar o trabalho do assistente social no âmbito do Sistema Único de Assistência Social (Suas), pela oportunidade de problematizar um processo que está em curso em todo o país, e que pela velocidade e complexidade apresenta desafios às profissões envolvidas que precisam ser acompanhados e desvendados criticamente.

Apesar de a assistência social ser uma das mediações mais tradicionais e persistentes do exercício profissional, considera-se que a implantação do Suas

2. Aqui se insere um amplo e polêmico debate atual a respeito do Serviço Social como trabalho e do assistente social como trabalhador assalariado, que não cabe neste momento aprofundar. Cf. Iamamoto, 2007, e Lessa, 2007. 
amplia as possibilidades de trabalho profissional nos novos espaços ocupacionais, como os Centros de Referência de Assistência Social (Cras) e os Centros de Referência Especializados de Assistência Social (Creas), além de demandar o desenvolvimento de novas habilidades e competências para a gestão pública nos âmbitos da assessoria, planejamento, avaliação, monitoramento, entre outras. Trata-se, pois, de demandas profissionais que desafiam os assistentes sociais a formular mediações teóricas, técnicas, éticas e políticas, na perspectiva da competência crítica diante das exigências burocráticas e administrativas que lhe são requeridas, de modo a não sucumbir ao discurso competente (Chaui, 1989) autorizado e requisitado pelas instâncias burocráticas das instituições empregadoras.

Descartando, portanto, qualquer visão unilateral e buscando romper com os conhecidos pares dicotômicos na reflexão sobre o trabalho do assistente social - voluntarismo/determinismo, politicismo/economicismo, conservadorismo/transformação, entre outros, e com base em Iamamoto (1982), partimos do suposto que apreender os espaços sócio-ocupacionais que se abrem ao exercício profissional para capturar a lógica de retração ou intensificação de demandas em determinadas áreas, como a que ocorre atualmente com a política de assistência social, bem como as respostas individuais e coletivas dos assistentes sociais às novas exigências institucionais, exige desvelar o caráter contraditório do Serviço Social como prática polarizada pelos interesses das classes sociais, que tanto participa dos mecanismos de manutenção quanto de mudança, respondendo a interesses do capital e também do trabalho, participando dos processos de dominação e de resistência, continuidade e ruptura da ordem social, como bem analisou Iamamoto em sua ampla e significativa produção bibliográfica sobre o Serviço Social na sociedade capitalista madura. ${ }^{3}$

O trabalho do assistente social é, pois, a expressão de um movimento que articula conhecimentos e luta por espaços no mercado de trabalho, competências e atribuições privativas que têm reconhecimento legal nos seus estatutos normativos e reguladores (regulamentação profissional, código de ética, diretrizes curriculares da formação profissional), projeto ético-político que confere direção social ao trabalho profissional. Ao mesmo tempo, os sujeitos que a exercem, individual e coletivamente, se subordinam às normas de enquadramento insti-

3. Entre outros, consultar especialmente Iamamoto e Carvalho, 1982; Iamamoto, 1998, e Iamamoto, 2007. 
tucional, mas também se organizam e se mobilizam no interior de um coletivo de trabalhadores que repensam a si mesmos e a sua intervenção no campo da ação profissional.

É nesse processo tenso que as profissões constroem seus projetos profissionais, no caso do Serviço Social, o projeto ético-político profissional que há pelo menos três décadas vem sendo formulado coletivamente pelo Serviço Social brasileiro.

Os projetos profissionais apresentam a autoimagem de uma profissão, elegem os valores que a legitimam socialmente, delimitam e priorizam seus objetivos e funções, formulam os requisitos (teóricos, práticos e institucionais) para o seu exercício, prescrevem normas para o comportamento dos profissionais e estabelecem as bases das suas relações com os usuários de seus serviços, com as outras profissões e com as organizações e instituições privadas e públicas (inclusive o Estado, a quem cabe o reconhecimento jurídico dos estatutos profissionais. (Netto, 2006, p. 144)

Esse projeto, que tem por base um sujeito coletivo, exige organização de um corpo ou categoria profissional por meio do conjunto dos seus agentes profissionais, docentes, pesquisadores, estudantes e organismos profissionais, e é resultado de conjunturas e dinâmicas sociopolíticas particulares, que reforçam a estreita vinculação entre a definição e a ampliação dos espaços de trabalho dos assistentes sociais e as manifestações da questão social. ${ }^{4}$

No Brasil, notadamente a partir dos anos 1980, marco da construção do projeto de ruptura com o conservadorismo, assiste-se ao agravamento da questão social e suas dramáticas expressões a incidir no cotidiano de vida e trabalho de indivíduos, grupos, famílias, coletividades com os quais o Serviço Social trabalha, na luta pela reprodução social em suas múltiplas dimensões materiais, subjetivas, relacionais, espirituais.

As políticas sociais, como mediação fundamental da ação do Estado, viabilizam uma intervenção continuada e estratégica sobre as sequelas da questão social, levando o aparelho estatal a desenvolver simultaneamente funções eco-

4. A questão social, tal como a entendemos, é a expressão das desigualdades sociais produzidas e reproduzidas na dinâmica contraditória das relações sociais, e, na particularidade atual, a partir das configurações assumidas pelo trabalho e pelo Estado, no atual estágio mundializado e financeirizado do capitalismo contemporâneo. Para aprofundamento consultar Netto, 1992, e Iamamoto, 2007. 
nômicas, políticas e sociais, administrando as contradições e buscando um sistema de consensos em busca de legitimidade social.

Simultânea e dialeticamente, as políticas sociais representam a face da luta dos movimentos sociais, expressando a dimensão de conquista das classes trabalhadoras decorrente das pressões e mobilizações em busca de respostas a necessidades sociais de reprodução social, ainda que estas sejam invariavelmente insuficientes e limitadas.

As respostas do Estado à questão social se realizam por meio de um sem-número de organizações sociais, por meio da fragmentação e setorização das necessidades sociais (daí as políticas sociais no plural), recortando-as em problemas sociais "particulares" como o desemprego, a fome, o analfabetismo, a doença etc.), dificultando a explicitação de sua raiz comum numa perspectiva de totalidade, provocando a atomização das demandas e a competição entre os segmentos demandantes do acesso a parcelas do fundo público.

A própria implementação das políticas sociais também é um jogo complexo de conflitos e tensões, que envolve diferentes protagonistas, interesses, projetos e estratégias, contexto em que são requisitadas a presença e a intervenção de diferentes categorias profissionais que disputam espaços de reconhecimento e poder no interior do aparelho institucional.

Nesses termos, torna-se importante romper com qualquer linearidade na análise das políticas sociais e dos espaços ocupacionais nos quais se inserem os assistentes sociais, ainda mais considerando as formas de enfrentamento do capital às suas crises de acumulação, que aprofundam e agravam as manifestações da questão social, mas também desencadeiam respostas da sociedade e do conjunto das classes trabalhadoras em seu movimento de resistência e defesa de direitos conquistados historicamente.

Ainda que requerendo maior aprofundamento, o que escapa aos limites deste texto, é preciso lembrar que os anos 1990 foram palco de um complexo processo de regressões no âmbito do Estado e da universalização dos direitos, desencadeando novos elementos que se contrapõem ao processo de democratização política, econômica e social em nosso país, no contexto de crise e reorganização do capitalismo em escala internacional.

Esse quadro desencadeia profundas transformações societárias, determinadas pelas mudanças na esfera do trabalho, pela reforma gerencial do Estado ou contrarreforma (nos termos de Behring, 2003), pelos processos de redefini- 
ção dos sistemas de proteção social e da política social que emergem nessa conjuntura, e pelas novas formas de enfrentamento da questão social, com grandes mudanças e rebatimentos nas relações público-privado.

De um lado, observa-se o processo de destituição de direitos no rastro da reforma conservadora do Estado e da economia, que desencadeia um crescente e persistente processo de sucateamento dos serviços públicos, de ofensiva sistemática contra os novos direitos consagrados na Constituição de 1988, a partir de ampla mobilização de forças sociais que lutaram pela democratização da sociedade e do Estado no Brasil.

De outro, mais além dessas destituições, o que está em curso é o esvaziamento da própria noção de direitos relacionado a uma suposta desnecessidade de tudo que é público e estatal. Nas palavras de Vera Telles (1994), trata-se do "encolhimento do horizonte de legitimidade dos direitos", que transforma direito em privilégio em nome da necessária modernização da economia, cuja referência maior é o mercado e suas demandas e prerrogativas.

O agravamento da questão social decorrente do processo de reestruturação produtiva e da adoção da programática neoliberal repercute no campo profissional, tanto nos sujeitos com os quais o Serviço Social trabalha - os usuários dos serviços sociais públicos — quanto no mercado de trabalho dos assistentes sociais que, como o conjunto dos trabalhadores, sofrem o impacto das metamorfoses que afetam o trabalho assalariado na contemporaneidade, submetendo a atividade profissional aos dilemas da alienação (Iamamoto, 2007 e 2009). Trata-se de uma dinâmica societária que atinge as diferentes profissões, e também o Serviço Social, que tem nas políticas sociais um campo de intervenção privilegiado.

As transformações nos espaços ocupacionais do assistente social têm origem nesses processos macrossocietários e põem em relevo as específicas condições e relações de trabalho no contexto mais geral de mudanças e constituição da nova morfologia do trabalho (Antunes, 2005). Uma das expressões dessas mudanças decorre das alterações na base técnica de produção por meio da incorporação das denominadas TICs (Tecnologias de Informação e Comunicação) e demais inovações tecnológicas que induzem novas relações e modos de gestão do trabalho, desencadeando processos de intensificação do trabalho (Dal Rosso, 2008) e aumento da produtividade nas mais diversas áreas, não só nas diretamente produtivas, mas também no campo da formulação, gestão e prestação de serviços sociais públicos. 
Verifica-se, assim, que a reestruturação produtiva em curso atinge o mercado de trabalho do assistente social, incidindo contraditoriamente tanto na mudança e/ou redefinição de postos de trabalho em algumas áreas (por exemplo, nas empresas), como também na ampliação e diversificação, como é o caso das políticas de seguridade social, especialmente a política de assistência social. Esta dinâmica é ainda mais intensa em âmbito municipal, considerando as novas requisições que chegam aos municípios em virtude da descentralização e municipalização dos serviços sociais públicos, e diante das inúmeras pressões que sofrem diretamente das populações atingidas pelo desemprego, pobreza, violência, insegurança do trabalho e da moradia.

\section{A nova morfologia do trabalho - tensões entre projeto profissional e trabalho assalariado}

Dados da pesquisa sobre perfil do assistente social no Brasil promovida pelo conjunto CFESS/Cress (2005) demonstram que os assistentes sociais continuam sendo predominantemente trabalhadores assalariados, notadamente de organismos governamentais, com maior incidência nas políticas de saúde e assistência social. A maioria dos assistentes sociais é de servidores públicos, sendo que $78,16 \%$ atuam em organizações de natureza estatal, $40,97 \%$ na esfera municipal, $24 \%$ nos estados e $13,19 \%$ em âmbito federal.

Embora seja necessária a atualização desses dados, ${ }^{5}$ outros estudos de caráter regional, estadual ou local que têm sido realizadas mais recentemente ${ }^{6}$ apontam para a permanência desse quadro, com predominância da inserção dos profissionais em órgãos municipais, indicando ainda um crescimento na esfera federal.

5. A pesquisa "Assistentes sociais no Brasil: elementos para estudo do perfil profissional" (CFESS, 2005) foi realizada pela Ufal com apoio dos Cress em maio de 2004, com os assistentes sociais regularmente inscritos nos conselhos regionais, tendo como universo um contingente de 61.151 profissionais. Com um universo atual de quase 90 mil profissionais é urgente a necessidade de atualização desta pesquisa.

6. As pesquisas apresentadas no colóquio "Trabalho na sociedade contemporânea e o trabalho do assistente social", promovido pela Rede de Pesquisa sobre Trabalho do Assistente Social (Retas), realizado na Universidade Federal de Alagoas em maio de 2010, reafirmam muitas das características apontadas na investigação de 2005, ao mesmo tempo em que indicam a tendência à precarização do trabalho do assistente social em diferentes espaços sócio-ocupacionais. 
Em um contexto social marcado pela retração e mesmo erosão do trabalho contratado e regulamentado, típico da era taylorista e fordista, cresce o trabalho precário, parcial, temporário, bem como as diferentes modalidades de flexibilização de vínculos e de direitos, além da ampliação do trabalho voluntário e das diversas formas de cooperativismo e empreendedorismo, que ocultam novos modos de gestão e (auto)exploração do trabalho.

Presencia-se também a explosão do desemprego estrutural em escala global, que atinge a totalidade dos trabalhadores, sejam homens e mulheres, estáveis ou precarizados, formais ou informais, e a deterioração da qualidade do trabalho, dos salários e das condições em que ele é exercido. ${ }^{7}$

As condições atuais do capitalismo contemporâneo - globalização financeirizada dos capitais e sistemas de produção apoiados fortemente no desenvolvimento tecnológico - promovem intensas mudanças nos processos de organização, gestão e nas relações e vínculos laborais da classe-que-vive-do-trabalho (Antunes, 1999), resultando em "nova morfologia do trabalho", com amplos contingentes de trabalhadores flexibilizados, infornalizados, precarizados, pauperizados, desprotegidos de direitos e desprovidos de organização coletiva (Antunes, 2005).

São contextos que geram processos continuados de informalização e flexibilização expressos por trabalhos terceirizados, subcontratados, temporários, domésticos, em tempo parcial ou por projeto, para citar apenas algumas das diferentes formas de fragilização a que está submetida a classe trabalhadora. São transformações que atingem duramente o trabalho assalariado, sua realização concreta, sua materialidade e as formas de subjetivação na consciência dos trabalhadores, levando a redefinições dos sistemas de proteção social e das formas de organização e gestão dos processos de trabalho.

Essa dinâmica de precarização atinge também o trabalho profissional do assistente social, afetado pela insegurança do emprego, precárias formas de contratação, intensificação do trabalho, baixos salários, pressão pelo aumento da produtividade e de resultados imediatos, ausência de horizontes profissionais de mais longo prazo, falta de perspectivas de progressão e ascensão

7. Um amplo estudo sobre a reestruturação produtiva no Brasil e dos mecanismos de terceirização, subcontratação, precarização do trabalho que afetam a classe trabalhadora no país, por meio da investigação empírica em diversos setores ou ramos econômicos, pode ser encontrado em Antunes (2006). 
na carreira, ausência de políticas de qualificação e capacitação profissional, entre outros. $^{8}$

No âmbito do Serviço Social, intensifica-se a subcontratação de serviços individuais dos assistentes sociais por parte de empresas de serviços ou de assessoria, de "cooperativas" de trabalhadores, na prestação de serviços aos governos e organizações não governamentais, acenando para o exercício profissional privado (autônomo), temporário, por projeto, por tarefa, em função das novas formas de gestão das políticas sociais.

As consequências desses processos para o trabalho social nas políticas públicas são profundas, pois a terceirização desconfigura o significado e a amplitude do trabalho técnico realizado pelos assistentes sociais e demais trabalhadores sociais, desloca as relações entre a população, suas formas de representação e a gestão governamental, pela intermediação de empresas e organizações contratadas. Além disso, as ações desenvolvidas passam a ser subordinadas a prazos contratuais e aos recursos financeiros destinados para esse fim, implicando descontinuidades, rompimento de vínculos com usuários, descrédito da população para com as ações públicas.

O que é ainda mais grave nesse contexto de terceirização dos Serviços Sociais públicos é que se trata de um mecanismo que opera a cisão entre serviço e direito, pois o que preside o trabalho não é a lógica pública, obscurecendo-se a responsabilidade do Estado perante seus cidadãos, comprimindo ainda mais as possibilidades de inscrever as ações públicas no campo do direito. Consolida-se assim o que Vieira (1997) denominou de "política social sem direitos sociais", uma espécie de nova morfologia da política social.

Portanto, a partir dos anos 1990 e adentrando a primeira década dos anos 2000, o campo das políticas públicas e a luta por direitos ficaram muito mais complexos, especialmente se considerarmos que, apesar de todos os desmontes e desmanches que têm atingido a esfera estatal, o Estado permanece sendo a forma mais efetiva de operar a universalização dos direitos, mesmo em sociedades capitalistas periféricas e financeirizadas como a brasileira.

8. Mesmo diante de uma conjuntura adversa aos direitos do trabalho e aos trabalhadores, os assistentes sociais conseguiram uma significativa vitória com a recente aprovação pelo Senado Federal do PLC n. 152/2008, sancionado pelo presidente Lula no dia 26 de agosto de 2010, que implanta a jornada de trabalho de trinta horas sem redução salarial. A partir de agora a luta, que será árdua, é pela implementação da lei fazendo valer este direito para todos(as) os(as) assistentes sociais do país em todos os municípios da federação. 


\section{0 trabalho do assistente social no Suas - ampliação, intensificação e precarização}

Como tem sido amplamente analisado, a política de assistência social, desde que foi incorporada ao tripé da Seguridade Social nos marcos da Constituição Federal de 1988, juntamente com a Saúde e a Previdência Social, vem experimentando um continuado e expressivo movimento reformador, desencadeado com a Loas/1993, com grande inflexão a partir da PNAS/2004 e da NOB-Suas/2005. Esse novo marco regulatório introduziu significativas alterações, entre elas a exigência de novos modos de organização, processamento, produção e gestão do trabalho.

A questão do trabalho e dos trabalhadores no Suas é um dos grandes desafios a ser enfrentado, se o objetivo for a implementação da política de assistência social voltada para o atendimento de necessidades sociais e comprometida com a ampliação e a consolidação de direitos das classes subalternas.

Se este é um desafio para toda a administração pública brasileira, em função das questões que atingem o mundo do trabalho, o Estado e as políticas públicas na contemporaneidade, inegavelmente assume características específicas na assistência social, pelo seu histórico de desprofissionalização e de atuação com base em estruturas improvisadas e descontínuas, do qual são expressões emblemáticas a cultura autoritária, patrimonialista e clientelista e o primeiro-damismo persistente e (re)atualizado nesta área, indicando possivelmente a adoção de novas estratégias de (re)legitimação desse instituto. ${ }^{9}$ Acrescente-se a isso a realidade da maioria dos municípios brasileiros que, sendo de pequeno porte, contam com frágeis estruturas institucionais de gestão, rotinas técnicas e administrativas incipientes e recursos humanos reduzidos e pouco qualificados.

9. A pesquisa Perfil dos municipios brasileiros — suplemento de assistência social, Munic/IBGE (2010), recém-publicada, apresenta dados significativos sobre a persistência dessa cultura patrimonialista na assistência social. Dentre os municípios que declararam ter órgão gestor da assistência social, 1.352 responderam que a política de assistência social naqueles municípios era conduzida pela primeira-dama, num total de $24,3 \%$ dos municípios brasileiros. Chama a atenção ainda o movimento de primeiras-damas em busca de qualificação universitária: 47,4\% destas gestoras possuíam o ensino superior completo e/ou pós-graduação, com maior incidência nas seguintes formações: 45 assistentes sociais, 194 pedagogas, 42 advogadas, 43 administradoras e 257 com formações variadas não discriminadas no questionário. 
Do ponto de vista da constituição dos quadros profissionais do Suas, destaca-se ainda o universo heterogêneo de trabalhadores, compostos por servidores e trabalhadores da esfera estatal nos três níveis de governo, e pela extensa "rede" privada de entidades de assistência social, com uma diversidade de áreas de formação, acúmulo teórico-prático, vínculos e condições de trabalho. Tais quadros se disseminam com grande discrepância pela realidade heterogênea de estados e municípios, sendo frequente a existência de um número mínimo e insuficiente de profissionais, em geral com grandes defasagens teóricas e técnicas, atuando simultaneamente em diferentes políticas e programas, e até mesmo em vários municípios limítrofes. ${ }^{10}$

Por ser uma área de prestação de serviços cuja mediação principal é o próprio profissional (Sposati, 2006), o trabalho da assistência social está estrategicamente apoiado no conhecimento e na formação teórica, técnica e política do seu quadro de pessoal, e nas condições institucionais de que dispõe para efetivar sua intervenção. ${ }^{11}$

A implantação do Suas exige novas formas de regulação, organização e gestão do trabalho e, certamente, a ampliação do número de trabalhadores com estabilidade funcional é condição essencial, ao lado de processos continuados de formação e qualificação, a partir do ingresso via concurso público, definição de cargos e carreiras e de processos de avaliação e progressão, caracterização de perfis das equipes e dos serviços, além de remuneração compatível e segurança no trabalho.

Nesses termos, a Norma Operacional Básica de Recursos Humanos do Sistema Único de Assistência Social (NOB-RH/Suas), instituída pela Resolução CNAS n. 269, de 13 de dezembro de 2006, representou um ganho político significativo na pactuação federativa entre gestores da política de assistência social e na luta dos seus trabalhadores por condições materiais, técnicas e éticas de trabalho nos órgãos gestores, nos Cras e Creas e nas entidades de assistência

10. Dados da pesquisa Munic/IBGE (2010) sobre qualificação dos técnicos de nível superior apontam que dos 3.376 (58,9\%) gestores com superior completo e/ou pós-graduação, 29,6\% eram assistentes sociais, $21,7 \%$ pedagogos, $26,7 \%$ tinham outra formação não discriminada no questionário, e $22 \%$ estavam assim distribuídos: 6,9\% entre terapeutas ocupacionais, psicólogos, médicos enfermeiros ou nutricionistas; e 15\% entre sociólogos, advogados, jornalistas, administradores, economistas e contabilistas.

11. Referimo-nos aqui especificamente ao trabalho de profissional de nível universitário, sem desconhecer o grande e crescente contingente de trabalhadores de nível médio que atuam no Suas em diferentes cargos e atividades, muitas vezes substituindo o trabalho especializado de profissionais. 
social vinculadas ao Suas, consideradas as resistências e dificuldades políticas que tiveram que ser aparadas para viabilizar sua aprovação.

Mesmo distante das requisições exigidas em termos de recursos humanos e de condições materiais para o funcionamento adequado do Suas, a NOB-RH/ Suas foi resultado da correlação de forças políticas presentes nos processos de negociação e pactuação que levaram à sua aprovação. Apesar disso, permanece ainda o grande desafio de sua efetivação na maioria dos estados e municípios brasileiros, que apresenta por parte dos gestores, prefeitos e secretários de governo bastante resistência, além de desconhecimento da NOB/Suas/RH e das exigências para sua implementação. ${ }^{12}$

A NOB-RH/Suas prevê a formação de equipes de referência, que devem ser constituídas por servidores efetivos responsáveis pela organização e oferta de serviços, programas, projetos e benefícios de proteção social básica e especial, levando-se em consideração o número de famílias e indivíduos referenciados por porte dos municípios, tipo de atendimento e aquisições e direitos que devem ser garantidos aos usuários.

Dados da Munic/IBGE (2006) revelavam que 25\% dos trabalhadores da área de assistência social nas administrações municipais de todo o país não possuíam vínculos permanentes, sendo $20 \%$ comissionados e apenas $38 \%$ estatutários. Mais reveladores ainda foram os dados de 2007 extraídos da ficha de monitoramento dos Cras (MDS, 2008, p. 30, Tabela 11), que revelavam que 48,8\% dos trabalhadores dos Cras não tinham vínculos permanentes, sendo $25,8 \%$ estatutários, $13,5 \%$ CLT e $12 \%$ comissionados.

Comparando-se esses dados com os apresentados pela Munic-IBGE (2010), verificamos que apesar da elevação em $30,7 \%$ do total de pessoas ocupadas na administração municipal da assistência social em todo o país, no período 2005-09 a política de assistência social continuava sendo responsável por apenas 3,2\% de todo o pessoal ocupado nas administrações públicas municipais.

12. É importante que se afirme que o Suas ainda não se transformou em lei no país, o que confere a este sistema único grande fragilidade política em termos de enraizamento estatal e garantia de permanência, considerando o traço de descontinuidade e personalismo que caracteriza as políticas públicas no Brasil. O PL Suas em tramitação no Congresso Nacional apresenta um dispositivo estratégico para avançar no cumprimento da NOB-RH, quando define em um dos seus artigos a possibilidade de repasse de recursos do Fundo Nacional de Assistência Social para financiar a contratação de trabalhadores da assistência social pelos municípios brasileiros, desde que concursados e efetivados como servidores públicos municipais. 
Contudo, mais revelador da tendência atual de precarização do trabalho assalariado no Suas são os dados relativos à estrutura trabalhista por vínculo empregatício: apesar de não serem identificadas grandes mudanças em relação aos dados de 2005 (a maioria continua sendo composta por servidores estatutários), a maior elevação foi detectada entre os trabalhadores sem vínculo permanente, que em 2005 totalizavam 34.057 pessoas, ampliando para 60.514 em 2010, ou seja, um aumento de 73,1\%; também o grupo de celetistas sofreu um decréscimo de 12,8\% em 2005 para 8,5\% em 2009.

Portanto, uma questão relevante a ser destacada quando se problematiza a situação do trabalho e dos trabalhadores na assistência social é que não se trata apenas de questões relacionadas à gestão do trabalho, mas fundamentalmente dos modos de organização do trabalho na sociedade capitalista contemporânea, e das condições concretas em que se realiza, particularmente nas políticas sociais, que, como a assistência social, tiveram um grande crescimento nesses últimos anos.

Nesse contexto é preciso observar também que a reforma neoliberal do Estado brasileiro implantada no governo FHC trouxe com ela intensa campanha ideológica de desconstrução do Estado e de "tudo que é estatal", acompanhada da satanização do Estado e supervalorização do mercado e de "tudo que é privado" nos âmbitos federal, estadual e municipal, atingindo duramente as condições e relações de trabalho nos espaços governamentais.

A ambiência neoliberal afetou também a imagem do servidor público e as representações sociais junto à população e à opinião pública, instalando-se um clima desfavorável à recomposição e expansão da força de trabalho na administração pública, embora nesse últimos anos seja possível observar certo avanço nessa direção, especialmente em nível federal.

Basta verificar como os jornais de grande circulação veiculam a realização de concursos públicos e a ampliação da contratação de funcionários públicos em qualquer esfera da administração pública: termos como inchaço da máquina, cabide de emprego, ampliação do déficit público, aumento da ineficiência etc. são comuns nas manchetes desses veículos de comunicação, que, simultânea e contraditoriamente, cobram do Estado mais e melhores serviços públicos.

Segundo análise de Amir Khair (2010):

O que está por trás desta visão é que o Estado é um mau aplicador de recursos ao contrário do setor privado. Assim, quanto menor a despesa com o Estado, mais 
recursos sobrarão para o setor privado desenvolver suas atividades. É uma política minimalista do Estado, não apenas em seu tamanho, mas também em sua interferência na vida econômica das empresas.

A questão que se apresenta é: como responder à ampliação da demanda por políticas sociais sem a existência de servidores públicos em número e qualificação exigidos para a prestação de serviços de qualidade enquanto direitos de cidadania das classes trabalhadoras?

Em função desse quadro, a análise das condições de trabalho e das possibilidades de sua ampliação e qualificação no âmbito do Suas não pode ser desvinculada dessa dinâmica macrossocietária, nem pode ser tratada como uma responsabilidade individual do trabalhador, embora seja comum atribuir ao próprio profissional a tarefa de sua qualificação, ampliando a competição entre os próprios trabalhadores que atuam nas diferentes políticas públicas.

A assistência social é um setor intensivo de força de trabalho humana, como já observamos, o que representa um desafio para a criação de condições adequadas de trabalho e de sua gestão institucional. Considerando as definições da NOB-Suas-RH, as equipes de referência para os Cras e os Creas envolvem um conjunto diversificado de profissões, atribuições e competências, instalando-se nova divisão sociotécnica do trabalho no âmbito do Suas.

Trata-se de um processo de grande complexidade, pois cada uma das categorias profissionais envolvidas tem uma história particular de organização e de luta corporativa e sindical, com acúmulos e reivindicações específicas no que tange às condições de exercício do trabalho, aos conhecimentos e saberes construídos, aos parâmetros ético-políticos orientadores do trabalho profissional.

Nessa perspectiva, é preciso considerar a ótica do trabalho coletivo no Suas:

- o trabalho nos Cras e Creas como trabalho social e combinado;

- orientado por projetos profissionais que podem convergir mas também se contrapor;

- que incorpora o acúmulo e as contribuições das diferentes profissões;

- mas que deve assimilar criticamente os conhecimentos e aportes daquelas que, como o Serviço Social, vem assumindo protagonismo histórico na elaboração de conhecimentos teóricos, técnicos e políticos que subsidiam os avanços da assistência social no país. 
Isto põe em debate a direção política do trabalho e a qualidade dos serviços socioassistenciais, na construção de processos interventivos que promovam protagonismos, particularmente dos usuários, para o fortalecimento da cultura democrática e de direitos.

Assim sendo, é fundamental no âmbito do Suas superar a cultura histórica do pragmatismo e das ações improvisadas, exercitando a capacidade de leitura crítica da realidade, sem reforçar naturalizações e criminalizações da pobreza e das variadas formas de violência doméstica e urbana, violação de direitos de crianças, adolescentes, mulheres, idosos, pessoas com deficiência, pessoas em situação de rua etc., mas procurando compreender criticamente os processos sociais de sua produção e reprodução na sociedade brasileira.

É preciso, pois, fazer a crítica e resistir ao mero produtivismo quantitativo, medido pelo de reuniões, número de visitas domiciliares, de atendimentos, sem ter clareza do sentido e da direção social ético-política do trabalho coletivo.

Por isso a luta pela garantia da qualificação e da capacitação continuadas, por espaços coletivos de estudo e de reflexão sobre o trabalho, de debate sobre as concepções que orientam as práticas, é parte da luta pela melhoria das condições de trabalho e da qualidade dos serviços prestados à população.

No caso da assistência social, as questões que envolvem as condições, relações e organização do trabalho ganham maior complexidade quando consideramos que grande parte dos serviços, programas e projetos é prestada por entidades de assistência social privadas que integram a rede socioassistencial nos territórios de abrangência dos Cras e Creas.

Muitas dessas entidades não realizaram ainda o reordenamento institucional exigido pelo Suas, inclusive em relação ao quadro de profissionais e condições de trabalho, resistindo ainda aos mecanismos de controle social e público. $\mathrm{E}$ as diretrizes e definições da NOB-Suas-RH se concentram majoritariamente nas instituições públicas, deixando em segundo plano e a descoberto as exigências que devem ser cumpridas pela ampla "rede" de serviços socioassistenciais privados.

Para integrar um sistema público estatal de assistência social, essas entidades e organizações sociais devem ser submetidas aos mesmos princípios e diretrizes que orientam o Suas, considerando o acesso ao fundo público para financiar atividades de assistência social por ela desenvolvidas (por meio de convênios e repasses diretos de recursos), e também as imunidades e isenções 
fiscais das entidades beneficentes que acessam o Certificado de Entidade Beneficente de Assistência Social - Cebas, recentemente regulado.

Os riscos presentes na implantação do Suas em efetivação em todo o país são apontados por Silveira (2009, p. 343):

As fragilidades presentes na gestão e na participação em âmbito local reforçam limitações que são constitutivas dos processos descentralizadores, revelando a tendência aos arranjos institucionais que podem banalizar o próprio Suas. Há uma tendência dos municípios e estados cumprirem requisitos mínimos para manter o financiamento sem necessariamente expressar qualidade na estruturação da rede socioassistencial e das condições institucionais de gestão

o que inclui o trabalho precário dos profissionais.

A NOB-RH/Suas avança no enfrentamento dessa realidade quando define mecanismos de profissionalização e publicização da assistência social, orientando procedimentos para composição de equipes básicas de referência para Cras e Creas, definindo diretrizes para a qualificação de recursos humanos e a ampliação da capacidade de gestão dos seus operadores.

Há também algumas diretrizes para a rede socioassistencial privada, no sentido da valorização dos seus trabalhadores, da capacitação técnica em consonância com a PNAS, de tratamento salarial isonômico entre trabalhadores da rede pública e das entidades prestadoras de serviço assistenciais, mas ainda muito fluidas para garantir condições concretas de trabalho comuns à rede socioassistencial, que deve ser única e integrada. Nessa perspectiva, há um longo caminho a ser percorrido.

O que está em questão, portanto, é a ressignificação do trabalho na assistência social, referenciada em um projeto coletivo de redefinição do trabalho, das formas de organização e gestão institucional que incorporem mecanismos permanentes de democratização, qualificação e capacitação continuada, como questão estratégica para a valorização da intervenção profissional no Suas.

Quanto mais qualificados os servidores e trabalhadores da assistência social, menos sujeitos a manipulação e mais preparados para enfrentar os jogos de pressão política e de cooptação nos espaços institucionais, conferindo qualidade e consistência ao trabalho realizado.

Ao mesmo tempo, é preciso discutir as estratégias de organização coletiva frente aos processos de precarização do trabalho, no contexto do conjunto dos 
trabalhadores da seguridade social e das políticas sociais em geral. Embora a perspectiva neoliberal se utilize de inúmeros mecanismos para dividir o conjunto dos trabalhadores e suas entidades coletivas, é por meio da ação coletiva que são criadas condições concretas para a melhoria das condições de trabalho:

Outra questão importante a ser analisada é a crescente informatização do trabalho, em todos os âmbitos em que ele se desenvolve, sendo hoje uma condição essencial para a organização e a gestão do trabalho no Suas e nas políticas sociais.

No caso do setor público, a exemplo do setor privado, as mudanças tecnológicas também estão sendo profundas em todos os níveis. O computador é o equipamento emblemático que sintetiza a transformação do aparato de recursos e sistemas. Sem desconsiderar sua importância e indispensabilidade na realidade atual, é preciso indagar: qual é o seu efeito sobre o trabalho dos servidores públicos?

Pesquisas junto às empresas e ao setor privado realizadas por Dal Rosso (2008) concluíram que as tecnologias de informação intensificam os processos de trabalho, produzem um efeito mais controlador sobre o trabalho, organizam e encadeiam as tarefas de modo que desapareçam os tempos mortos, quantificam as tarefas realizadas e permitem a avaliação fiscalizatória do desempenho, entre outros.

Esse mesmo autor observa que embora nas entrevistas realizadas com servidores públicos do Distrito Federal prevaleça o entendimento de que os dispositivos eletrônicos aliviaram o trabalho, que o desgaste físico é menor, que "a tecnologia ajudou muito porque antes era tudo feito manualmente", suas reflexões revelam que algumas formas de intensificação do trabalho vão sendo incorporadas gradativamente ao serviço público e talvez não estejam ainda claramente perceptíveis para o conjunto de servidores.

Segundo Dal Rosso (2008, p. 188), essas formas de intensificação se referem mais ao ritmo e à velocidade do trabalho, às cobranças e às exigências, ao volume de tarefas, às características do trabalho intelectual demandante, ao peso da responsabilidade. E o autor constatou que também na esfera estatal está em plena construção "a ideologia da gerência e da qualidade total, do erro zero, do trabalho a tempo justo, da eficiência das metas e dos resultados".

Por isso, por mais que seja imprescindível a incorporação das novas tecnologias de informação no trabalho das políticas sociais, é preciso analisar mais 
profundamente os impactos dessa revolução tecnológica na intervenção profissional e na relação dos assistentes sociais com os usuários e a população, e como isto vai incidindo nas representações dos usuários e na consciência e formas de subjetivação dos profissionais.

Sobre esta questão, são interessantes as observações de Úrsula Huws (2009), importante pesquisadora inglesa em um texto que analisa o impacto das mudanças tecnológicas nos processos de trabalho social:

Trabalhadores sociais, por exemplo, podem ver-se preenchendo formulários padrões numa tela de computador em vez de redigi-los no papel ou de entregar relatórios mais nuançados e profissionalmente qualificados para seus clientes; professores podem ver-se administrando testes padrões; [...] jornalistas de internet podem ser obrigados a escrever em apertados modelos predefinidos; e arquitetos podem ser reduzidos à tarefa de recombinar componentes padrões. (Huws, 2009, p. 47)

\section{Considerações finais}

Apesar dos limites e desafios aqui pontuados, a implantação do Suas em todo o território nacional abre um campo de novas possibilidades, tensas e contraditórias, ao trabalho profissional dos assistentes sociais:

1. A existência dos Cras e dos Creas como unidades públicas estatais cria oportunidade inédita de qualificação e articulação dos serviços, programas, projetos e benefícios voltados para o atendimento das necessidades sociais e direitos da população nos seus territórios de abrangência. É a presença do Estado nos territórios de moradia da população com direito de acesso a serviços e programas sociais públicos e de qualidade.

2. Ao mesmo tempo, a implantação do Suas evidencia os limites do trabalho assalariado dos assistentes sociais no campo das políticas públicas, exigindo estratégias políticas coletivas para o enfrentamento dos constrangimentos a que são submetidos na relação com os empregadores e dirigentes institucionais.

3. Os avanços do Serviço Social brasileiro e a direção ético-política da profissão recusam, contudo, a adoção de abordagens conservadoras, autoritárias ou disciplinadoras, que individualizam, moralizam ou patologizam/terapeutizam a questão social, culpabilizando ou criminalizando as famílias e indivíduos pela sua condição de pobreza. 
4. Os assistentes sociais, com base em sua autonomia profissional, ainda que relativa, e tendo em vista prerrogativas legais, éticas e técnicas, estão sendo desafiados a inovar e ousar na construção de estratégias profissionais que priorizem as abordagens coletivas e a participação dos usuários da assistência social, no sentido de reverter relações autoritárias e tuteladoras que subalternizam a população.

5. A consolidação do Suas exige novas formas de organização do trabalho, e certamente a ampliação do número de trabalhadores é condição essencial, ao lado de processos continuados de capacitação, realização de concursos públicos de ingresso, plano de cargos, carreira e salários, entre outros. Para isso, a luta pela efetiva concretização da NOB-RH/Suas é requisito importante a mobilizar os trabalhadores.

6. Por último, mas não menos importante, o Suas, na contramão do movimento societário nacional e internacional, supõe um Estado que recupere a capacidade de direção política e reconstrua as bases de legitimidade social junto à população, recusando-se, portanto, qualquer padrão minimalista para seu funcionamento, o que exclui a possibilidade de ampliação de serviços sociais públicos em detrimento da precarização do trabalho e da terceirização/privatização dos serviços públicos e dos seus operadores.

Para concluir, é necessário ressaltar as relações entre Serviço Social e política pública, entendendo-se que as políticas sociais são mediações fundamentais da profissionalização do Serviço Social, no entanto não se confundem com ela: é preciso reafirmar as diferenças entre Serviço Social como profissão e política pública como responsabilidade do Estado e dos governos. No caso da assistência social, embora seja uma mediação persistente que remonta às origens da profissão, o Serviço Social não pode ser confundido com a assistência social nem ser restringido a esse campo de intervenção profissional.

Essa compreensão é de fundamental importância para evitar o que Marilda Iamamoto (2007) identifica, com propriedade, como relação mimética entre políticas sociais e Serviço Social, diluindo e obscurecendo a visibilidade das particularidades das ações profissionais no âmbito dessas políticas.

Este mimetismo traz sérias consequências para o reconhecimento da identidade profissional e das particularidades da área de Serviço Social como campo de produção de conhecimentos. Nesses termos, é imperioso recuperar a centralidade de estudos e pesquisas que possam apreender o trabalho profissio- 
nal em suas múltiplas inserções, relações e alternativas no cenário atual, no contexto das transformações que se processam na esfera do trabalho de produção de bens e serviços sociais, nos âmbitos público e privado.

Finalizamos ressaltando que é na contracorrente do instituído que a categoria dos assistentes sociais vem construindo uma história de lutas e de resistência, apostando no futuro, mas entendendo que ele se constrói agora, no tempo presente.

Artigo recebido em ago./2010 - Aprovado em set./2010

\section{Referências bibliográficas}

ANTUNES, Ricardo (Org.). Riqueza e miséria do trabalho no Brasil. São Paulo: Boitempo, 2006.

ANTUNES, Ricardo. O caracol e sua concha: ensaios sobre a nova morfologia do trabalho. São Paulo: Boitempo, 2005.

. Os sentidos do trabalho: ensaio sobre a afirmação e negação do trabalho. São Paulo: Boitempo, 1999.

ANTUNES, Ricardo; BRAGA, Ruy (Orgs.). Infoproletários: degradação real do trabalho virtual. São Paulo: Boitempo, 2009.

CFESS/CRESS. Assistentes sociais no Brasil: elementos para o estudo do perfil profissional. Brasília, CFESS/Cress/Ufal, 2005.

BEHRING, Elaine. Brasil em contrarreforma: desestruturação do Estado e perda de direitos. São Paulo: Cortez, 2003.

BRASIL. Ministério do Desenvolvimento Social e Combate a Fome. Lei Orgânica de Assistência Social. Lei n. 8.742, de 7 de dezembro de 1993, publicada no Diário Oficial da União, Brasília, 8 dez. 1993.

Política Nacional de Assistência Social. Brasília, 2004.

. Norma Operacional Básica do Suas (NOB/Suas). Brasília, 2005.

. Norma Operacional Básica do Suas (NOB/Suas). Brasília, 2006.

. Linha de base do monitoramento dos Cras. Brasília: MDS; Secretaria de Avaliação e Gestão da Informação, Secretaria Nacional de Assistência Social, 2008.

CHAUI, Marilena. Cultura e democracia. São Paulo: Cortez, 1989. 
DAL ROSSO, Sadi. Mais trabalho! A intensificação do labor na sociedade contemporânea. São Paulo: Boitempo, 2008.

FERNANDES, Solange. Estado e politica de assistência social: particularidades do trabalho dos assistentes social nos centros de referência de assistência social no estado do Paraná. Tese (Doutorado em Serviço Social) — Pontifícia Universidade de São Paulo. São Paulo, 2008.

HUWS, Úrsula. A construção de um cibertariado? Trabalho virtual num mundo real. In: ANTUNES, Ricardo; BRAGA, Ruy (Orgs.). Infoproletários: degradação real do trabalho virtual. São Paulo: Boitempo, 2009.

IAMAMOTO, Marilda. O Serviço Social na contemporaneidade: trabalho e formação profissional. São Paulo: Cortez, 1998.

. Serviço Social em tempo de capital fetiche. São Paulo: Cortez, 2007.

. O Serviço Social na cena contemporânea. In: CFESS/ABEPSS (Orgs.). Direitos sociais e competências profissionais. Brasília: CFESS/Abepss, 2009.

. Espaços sócio-ocupacionais do assistente social. In: CFESS/ABEPSS (Orgs.). Direitos sociais e competências profissionais. Brasília: CFESS/Abepss, 2009.

; CARVAlHO, Raul. Relações sociais e Serviço Social no Brasil: esboço de uma interpretação histórico-metodológica. São Paulo: Cortez, 1982.

INSTRUMENTOS PARAA FISCALIZAÇÃO DO EXERCÍCIO PROFISSIONAL DO ASSISTENTE SOCIAL. Brasília: CFESS, 2007.

KHAIR, Amir. Visões Fiscais. O Estado de S. Paulo, São Paulo, 9 maio 2010.

LEGISLAÇÃO BRASILEIRA DO SERVIÇO SOCIAL. Lei de Regulamentação (Lei Federal n. 8662, de 7 de junho de 1993); Código de Ética Profissional do Assistente Social (Resolução CFESS n. 273, de 13 de março de 1993); Diretrizes Curriculares para o Curso de Serviço Social (Abepss, 8 de novembro de 1996); Resoluções CFESS, PLs em tramitação no Congresso Nacional. Brasília, CFESS.

LESSA, Sérgio. Trabalho e proletariado no capitalismo contemporâneo. São Paulo: Cortez, 2007.

MUNI/IBGE. Perfil dos Municípios Brasileiros. Pesquisa de Informações Básicas Municipais. Suplemento Assistência Social 2005. Rio de Janeiro: IBGE, 2006.

. Pesquisa de Informações Básicas Municipais. Suplemento Assistência Social 2009. Rio de Janeiro: IBGE, 2010.

NERY, Vânia B. O trabalho de assistentes sociais e psicólogos na política de assistência social: saberes e direitos em questão. Tese (Doutorado em Serviço Social) — Pontifícia Universidade de São Paulo. São Paulo, 2009. 
NETTO, José Paulo. A construção do projeto ético-político do Serviço Social. In: MOTA, A. E. et al. Serviço Social e saúde: formação e trabalho profissional. São Paulo: Cortez, 2006.

. Capitalismo monopolista e Serviço Social. São Paulo: Cortez, 1992.

PARÂMETROS PARA ATUAÇÃO DE ASSISTENTES NA POLÍTICA DE ASSISTÊNCIA SOCIAL. Série Trabalho e Projeto Profissional nas Políticas Sociais. Brasília: CFESS, 2009.

PARÂMETROS PARA ATUAÇÃO DE ASSISTENTES SOCIAIS NA SAÚDE. Série Trabalho e Projeto Profissional nas Políticas Sociais. Brasília: CFESS, 2010.

RAICHELIS, Raquel. O Trabalho do Assistente Social na esfera estatal. In: CFESS/ ABEPSS. Direitos sociais e competências profissionais, Brasília: CFESS/Abepss, 2009.

Democratizar a gestão das políticas sociais: um desafio a ser enfrentado pela sociedade civil. In: MOTA, A. E. et al. Serviço Social e saúde: formação e trabalho profissional. São Paulo: Cortez, 2006.

- Esfera pública e conselhos de assistência social: caminhos da construção democrática. São Paulo: Cortez, 1998.

; WANDERLEY, L. E. (Orgs.). A cidade de São Paulo: relações internacionais e gestão pública. São Paulo: Educ, 2009.

; EVANGELISTA, A. C. Sociedade civil, questão social e relações internacionais na cidade de São Paulo. In: RAICHELIS, Raquel; WANDERLEY, L. E. A cidade de São Paulo: relações internacionais e gestão pública. São Paulo: Educ, 2009.

SILVEIRA, Jucimeri I. Sistema Único de Assistência Social: institucionalidade e processos interventivos. Serviço Social \& Sociedade, São Paulo, n. 98, 2009.

SPOSATI, Aldaiza. O primeiro ano do Sistema Único de Assistência Social. Serviço Social \& Sociedade, São Paulo, n. 87, 2006.

TELLES, Vera da S. Sociedade Civil e a construção de espaços públicos. In: DAGNINO, E. (Org.) Anos 90: política e sociedade no Brasil. São Paulo: Brasiliense, 1994.

VIEIRA, Evaldo. As políticas Sociais e os direitos sociais no Brasil: avanços e retrocessos. Serviço Social \& Sociedade, São Paulo, ano XVIII, n. 53, 1997.

YAZBEK, Maria C.; MARTINELLI, Maria L.; RAICHELIS, R. O Serviço Social brasileiro em movimento: fortalecendo a profissão na defesa de direitos. Serviço Social \& Sociedade, São Paulo, n. 95, 2008. 